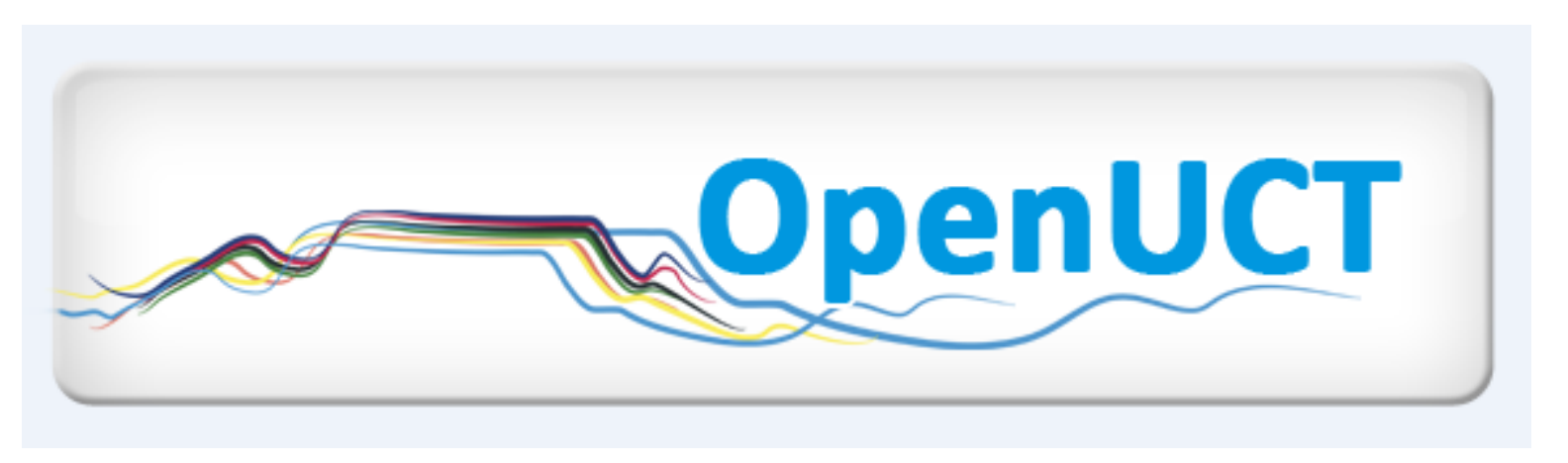

This is the author-approved manuscript version of a journal article published in:

Archer, A. H. 2008. 'The village of my childhood': nostalgia, narrative and landscape in an engineering course in South Africa. International Journal of Learning. 14(9): 147-154.

It is made available under the terms of agreement between the author and the journal, and in accordance with the University of Cape Town's Open Access Policy for the purposes of research, teaching and private study.

http://www.openuct.uct.ac.za/sites/default/files/UCTOpenAccessPolicy.pdf 


\title{
'The Village of My Childhood': Nostalgia, Narrative and Landscape in an Engineering Course in South Africa
}

\author{
Arlene Hillary Archer, University of Cape Town, Cape Town, South Africa
}

\begin{abstract}
About the Author
Dr. Arlene Hillary Archer

Arlene Archer is the co-ordinator of the Writing Centre at the Centre for Higher Education Development, University of Cape Town, South Africa. She teaches in Film and Media studies, as well as in an Engineering Foundation programme. She is interested in academic development in the tertiary environment - how diverse students from a range of language, class, cultural and gender identities access disciplinary knowledge. Her recent research focuses on the possibilities multimodal pedagogies may offer for enabling student access to Higher Education.
\end{abstract}




\title{
'The Village of My Childhood': Nostalgia, Narrative and Landscape in an Engineering Course in South Africa
}

\begin{abstract}
Different views of society, nature and technology inform engineering activity and proposed developmental interventions. This paper examines the discourses that students both draw on and propagate in a course on rural development in a first year engineering foundation programme. Students' texts reflect and recycle different discourses, some of which may complement each other, and others may compete or represent conflicting interests. A range of modes and media, coupled with the degree of regulation in the classroom space, may enable different discourses to emerge or to be further suppressed. This paper looks at the way rural is often constructed as 'lack' and therefore 'other', as well as discourses of nostalgia and utopianism and how these feed into notions of development. The agenda underlying this investigation is about facilitating student access to the engineering curriculum and contributing to the theorizing of a pedagogy of diversity that utilizes rather than ignores or devalues diverse subjectivities.
\end{abstract}

Keywords: Discourse Analysis, Pedagogy of Diversity, Nostalgia and Narrative, Multimodality, Rural Development

\section{Introduction}

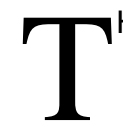

HE AGENDA UNDERLYING this research search is about facilitating student access to the engineering curriculum and contributing to the development of a pedagogy of

diversity that utilizes rather than ignores diverse subjectivities. The curriculum site is a Communication Course in an Engineering Foundation Programme that focuses on rural development in South Africa. Having taught this course for a number of years, I have become intrigued by the underlying views, beliefs and stories around development. The concept of rural is often constructed as 'lack' or as 'other' and this impacts on the type of development envisaged. Also, development is often seen as a linear process, which can result in various forms of nostalgia and utopianism, as well as the stereotyping of the rural poor as those who have not yet fully 'developed'. In this paper, I argue that it is important for the curriculum to engage with these views in order to understand, interrogate and critique the kinds of realities they feed into.

Rather than looking at 'development' as a linear process, it is important to look forward in the twenty first century, whilst at the same time examining how people draw on rooted experiences, and how they negotiate sometimes complex spaces. We need to draw on different knowledge traditions to show other possible ways of thinking about 'landscape' and human-nature interactions. This is not to imply that using knowledge of the past as a resource is a simplistic process of 'going backwards' or 'learning lessons'. Head asks: "How might we think differently about people. nature. environmental chanae and the past if we ... give voice to indigenous and local understandings?" (2000: 9). New competencies do not mean forgetting local and traditional life worlds. Theorists in the field of indigenous knowledge, like Nakata (2001), have written about the challenge for curriculum: how to acknowledge indigenous experience and expand on it. In thinking about rural development, students need to think about marrying their knowledge as engineers with local people's wisdom and needs, acknowledging this as a mutual process, not a top-down process.

\section{Uncovering Students' Discursive Struggles}

Bernstein (1996) talks about the symbolic barriers and thresholds between and within discourses in the classroom. He uses the concept of classification to examine relationships between categories, such as discourses and practices. He asks, in whose interest is the apartness of things? And in whose interest is togetherness and integration? These questions raise the issue of the relation of power to boundaries. Bernstein suggests that pedagogic discourse is constructed by a recontextualizing principle which "selectively appropriates, relocates, refocuses and relates other discourses to constitute its own order" (1996: 47). In this process of taking a discourse from its original site of effectiveness and moving it to a pedagogic site, a gap is created and an ideological transformation takes place.

Different modes and media, coupled with the degree of regulation in the classroom space, may enable different discourses to emerge or to be further suppressed. For instance, aspects such as views on 
childhood, relation to home, firmly held beliefs, were mentioned in the less regulated space of the oral interview, and were suppressed in the more regulated written and visual texts for assessment. What interests $m e$ is the degree of regulation of the oral, visual and written modes, and the affordances of these for expressing the more 'invisible' discourses that feed into students' views on development (see Archer 2006, 2007).

In order to uncover the discourses operating in the classroom, I concentrated on textual analysis, including the students' texts produced for assessment, interview data, and a general survey I conducted on the 80 students in the class (Archer 2004). I analyzed this data bearing in mind that all textual representations are social acts which take place within a particular institution, with a particular history, culture, set of values and practices. This is a point well established in the work of Halliday and other social semioticians. According to Halliday (1978), all semiotic systems operate as systems of social positioning at the level of interpersonal relationships and at the level of struggles for hegemony among social groups in any society. I take the view that human semiosis as an inherently social phenomenon, where meaning comes into being between participants rather than being transmitted from one to another.

A premise of this kind of analysis is that meaning is multiple and arises as a consequence of choice (Jewitt, Kress, and Ogborn 2000: 268). Thus, no text is ever monolithic without space for alternative visions. Texts reflect and recycle different discourses. Some of these differing discourses may complement each other, and others may compete with each other or represent conflicting interests or ideologies. In this paper I look at some of the survey data and interviews and focus on one student-produced poster on the course, specifically in terms of conflicting discourses.

\section{Site of Research}

Before discussing the data, I will firstly outline the larger context, and site of research. The Communication Course forms part of an academic development programme at a South African university. The students are diverse in terms of languages, home countries, age differences, rural and urban origins, gender. They enter university via an alternate access route with entrance criteria based on potential and not final school leaving grades, due to the inequitable educational opportunities afforded them. The academic development programme structures the students' learning experience by prolonging the period of study and by including courses aimed at developing academic literacy practices. The Communication Course is one such course and concentrates on developing academic literacy in English, as English is an additional language for most of the students.

The Communication Course is designed around a particular project, the Rural Village project, which introduces the idea of sustainability, seeing engineering as creating a more socially just and environmentally sustainable world. In teams of four, the students investigate the infrastructural and developmental needs of a particular rural settlement in South Africa, including aspects such as power, transportation, housing, water and sanitation. Their findings are presented in individual written reports and in a team-produced poster. When students form the groups, at least one team member needs to come from a rural area or have close knowledge of the village in question. In this way, reciprocity is set up as a principle in the groups. The person who has the knowledge of the village is to be used as a resource by the others. Thus, students exchange their mutual knowledges in an environment which values these. In the process, some notions of 'disadvantage' (including connotations around 'ruralness' discussed below) may actually be redefined in an environment of mutual respect.

\section{Rural as 'Lack'}

In the course, we work with notions of what the term 'rural' can mean and talk about the difficulties of defining a rural area. Rural/ urban seems to be a strong binary in South African society. Even though relatively few students on the course reported coming from a rural area (about 25\%), the reality in South Africa is that many students move between rural and urban settings. Urbanites often have family in rural areas due to South Africa's complex history of migrant labour as a result of artificially created 'reserves' or 'homelands'. The apartheid vision for these 'homelands' was that their populations were 'ethnic groups' that could be led through various stages of constitutional development towards the attainment of sovereign independence (Sharp 1988: 91). In reality, however, they were reserves for cheap labour, used particularly to service the mining industry. Apartheid spatial planning created a rural landscape devoid of economic opportunities and local markets and dependent on distant cities and towns for employment, goods and services.

I conducted a survey with the students in order to focus on perceptions of and attitudes to 'rural' and 'home'. These responses were explored further in interviews. One of the questions to the students was whether they reside in a rural area and if so, why they would define that area as rural. The responses can roughly be divided into the following categories:

- Emphasis on lack. Agriculture and cattle farming were mentioned as sources of income that 
distinguish rural areas from urban. However, this aspect of 'ruralness' was not overly emphasized in the responses; instead 'lack' was foregrounded, on many levels. Lack of infrastructure was specifically foregrounded: "Municipality is not responsible to bring services to the place"; "It just had electricity in the past two years" and "Not all the roads are tar roads. The water supply is not good". Lack was often couched in evaluative responses: "It has no night clubs, the life is dull and conservative".

- 'Non-western' nature of village. For example, "It is still developing and there are still mud houses".

- Location. For example, "It is far away from the city".

- Social organization. For example, "There are no town-councillors. There is only a chief"; "old method of family are used".

- Peoples' characters. For example, "People are disciplined".

The unclear boundaries between rural and urban are highlighted in the students' responses. For instance, one student who claimed to come from a rural area described it as "a sort of township". However, a 'township', the term commonly used for areas designated for black people under apartheid, is a distinctly urban area. The attempt to classify an area as 'rural' appears to activate this history of racial segregation as well as poverty. Two students from the same area, Umlazi in KwaZulu Natal, deined it differently, one classifying the area as rural, the other as urban.

The stereotypes and presuppositions attached to 'rural' in South Africa seem to be so strongly prevalent that some students, although describing themselves as 'rural', felt the need to define themselves against these stereotypes. Look at the following descriptions of Nqamakwe, Eastern Cape: "It is classified as a rural area, but the conditions we live under are better than those of rural areas" and this description of Ulundi, KwaZulu Natal: "It has no factories and firms and only one plaza but it is also a bit civilized" and this. Here the student feels compelled to reject presuppositions of what a rural area is like, and the judgements attendant on them (namely, 'uncivilized').

Although the students' definitions of 'rural' were contested and contradictory, there was also a strong communal sense of what rural South Africa looks like. A number of features were mentioned repeatedly, creating a common sense of a general description. Herds of cattle, goats and sheep were mentioned (even if only as a rural ideal, along with poor power supply, poor water supply and sanitation systems (outside toilets, no kitchen and bathroom water), animal transportation, grass and mud self-built housing, poor roads (mostly untarred), few shopping centres, schools, sports centres, hospitals, cultural centres, and poor access to advanced technologies. This description of rural South Africa from the students' responses describes the features of poverty in South Africa. The dire state of the rural areas partly stems from the long period of apartheid with its discriminatory policies and neglect of the majority black population. Current land ownership and land development patterns strongly reflect the political and economic conditions of the apartheid era. The unequal structure of land ownership is one of the most important determinants of the existing highly inequitable distribution of rural income and wealth, as well as the post-apartheid move to the cities after 'influx control' was dropped.

The struggle over definitions of the term 'rural' is crucial in raising an awareness of the conditions in rural areas, as well as the connotations around 'ruralness' and how these perceptions may feed into a development agenda.

\section{'Desires are Already Memories': Invisible Landscapes}

The Communication Course draws on the concept of 'landscape' in trying to tie together the ideas of 'rural', 'home' and society. Any landscape is the result of human activity and is therefore always social and cultural. 'The 'scape' in 'landscape' is related to the English word 'shape', and it is also related to the German word 'schaffen' - meaning both 'to work' and 'to create' " (Kress 1996: 33). This concept of 'landscape' highlights the way in which culture and nature, symbolism and materiality, past and present are clearly intertwined. On the course, 'landscape' refers to the physical space or built environment (the setting for rural villages), as well as to 'cultural landscapes' and 'communicational landscapes', where we make meaning from the resources available to us in that landscape.

Head discusses the meanings of the concept of 'cultural landscape'. The most common understanding of the term is that of landscape as ecological artefact, that is earth conceived of as transformed by human action (Head 2000: 55). However, there has been a change in the World Heritage definition of cultural landscapes to include the category of 'associative cultural landscape' which has emerged in "recognition of the intangible dimensions of landscape, and interactions between the physical and the spiritual / symbolic" (Head 2000: 83). In my understanding, all landscapes are cultural, and the concept covers the visual and material, as well as the symbolic environment. Of particular relevance to the concerns of the Communication Course is the interaction between the physical, social and symbolic dimensions of landscape. 
People inscribe themselves onto a landscape, and one of the ways of doing this is through selective memory. For example, in an interview with a student, Bantu, he spoke of the village the group had chosen for their research. Bantu grew up in that village, and said that in reconstructing it for his peers, he had constructed the village of his childhood, not the situation of the village as it is now. He mentioned the lack of electricity in the village, whereas the village is now fully electrified. He also spoke about his childhood memories of the relationship between people and animals, specifically cattle.

Before we used to look after cattle. Even where people have got their crops like maize and other stuff, we used to drive our cattle in there. We trained our cattle that it mustn't eat on the mealies, just the grass. When it starts to eat on the mealies, then you hit it, so that it must know, that is wrong. Ja, then it learns. You just whistle at them and then they turn around .... And sometimes when you look at that animal, it looks like you!

The sense of 'invisible' landscapes is captured well in Italo Calvino's fictional writing, Invisible Cities, where he describes how memory transforms landscapes.

When a man rides a long time through wild regions he feels the desire for the city. Finally he comes to Isidora, a city where the buildings have spiral staircases encrusted with spiral seashells, where perfect telescopes and violins are made, where the foreigner hesitating between two women always encounters a third, where cockights degenerate into bloody brawls among the bettors. He was thinking of all these things when he desired a city. Isidora, therefore, is the city of his dreams: with one difference. The dreamed-of city contained him as a young man; he arrives at Isidora in his old age. In the square there is the wall where the old men sit and watch the young go by; he is seated in a row with them. Desires are already memories. (Calvino 1979: 8)

This link between memory, desire, narrative and landscape is often symptomatic of nostalgia. "By the narrative process of nostalgic reconstruction, the present is denied and the past takes on an authenticity of being" (Stewart 1993: 23). As social actors, we are all involved in retelling our experiences and, in doing so, we chronicle our lives in terms of a series of events, happenings, influences and decisions. Narrative, as autobiography, describes the way in which people articulate how the past is related to the present. Time is placed into a personal history, where the past is given meaning in the present or, as Freeman (1998) points out, narrative may be the imposition of literary form upon that which is essentially formless, and perhaps meaningless. Social actors organize their lives and experiences through stories and in doing so make sense of them.

Powerful constructions of the physical, social and symbolic landscape are also often achieved through naming practices. One group of students analyzed a village called 'Nobody Village' which they claimed was the accepted name for the area. The student who came from Nobody, Mthoko, described the mythology behind the name. He said the village was named after one of the first white settlers in the area. Apparently, the last words uttered on this settler's solitary deathbed were 'Nobody is here'. The story behind the naming of the village has become mythologized through the perpetual re-telling, and the landscape is 'owned' and defined in a particular way by the assigned name. The story reflects on a colonial past as well as an existential state of abandonment and desolation. Naming of landscapes in South Africa is often fascinating in this way, including names such as 'Vergenoegd' (Far Enough), 'Welgevond' (Well Found) and 'Blerrie ver' (Bloody Far). Through bringing some of these 'invisible' cultural landscapes to the forefront of discussion, the course attempts to situate particular cultural practices within the broader systems of meaning and values that sustain them, and attempts to highlight cultural practices as complex sets of meaning that are sometimes in tension with each other.

\section{Student Poster on Efolweni Village}

To identify the ways in which students construct the relationships between society, nature and technology, I will look in some depth at a poster produced by one group of students on the course, namely the Efolweni Village poster (see figure 1). As mentioned earlier, I analyze this poster in terms of a social semiotic multimodal framework which focuses on the relationship between texts and the social practices they realise. By multimodal, I mean "the multi-semiotic complexity of a construct or practice" (ledema 2003: 40). In other words, any text combines different modes, such as the visual and the verbal, in particular ways.

The Efolweni Village poster is organized along a set of binaries, a 'before' and 'after' scenario. The 'before' scenario represents the problems experienced in the village. The children present a dire situation. The older boy is helplessly sucking his thumb and the younger boy is pointing at the dried up tap, presenting the situation to the viewer. The 'after' scenario shows suggested proposals to address the problems, followed by the 'outcomes', the proposed future for the 
inhabitants of the village. The children are presented in relation to each other; they are preoccupied with their own activities and are oblivious to the presence of the viewer. The dry earth is transformed from an area of hardship to a designated play area.

At times in the Efolweni Village poster there is a conflation of terms which is symptomatic of some of the confusion around the definition of 'rural' that circulated in the class: "The whole village is full of informal settlements made of mud". 'Informal settlements' is the term used to refer to the areas outside a city where houses are made of make-shift materials and there is no infrastructure. It is uncommon to refer to a rural village with mud houses as an 'informal' settlement. 'Informal' is a euphemism for 'squatter camp' and implies new and temporary, whereas the villages are more permanent and have a longer history.

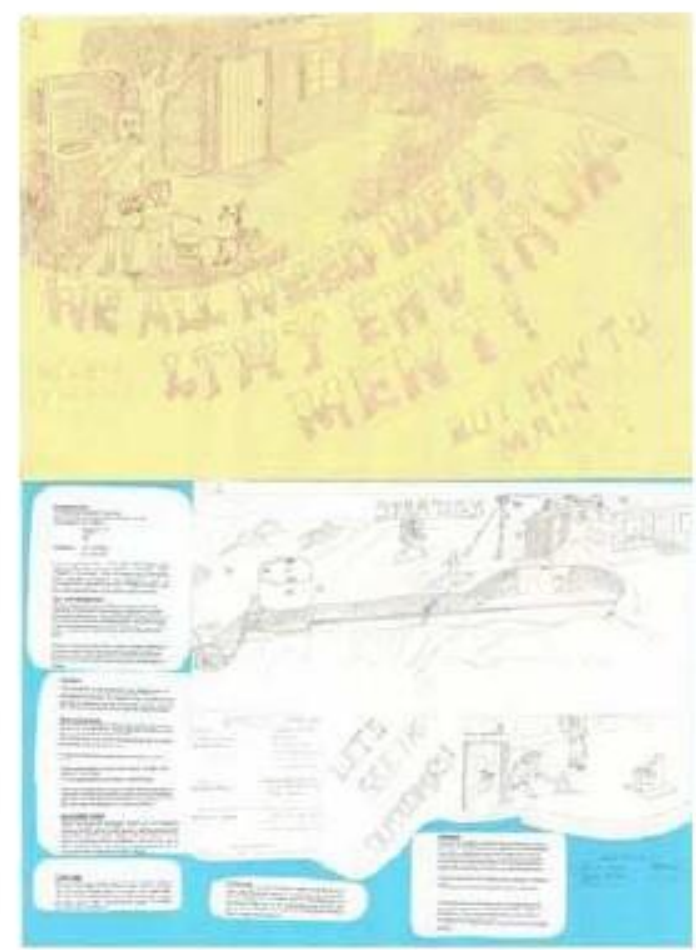

Figure 1: Efolweni Village Poster

\section{Development as Boundaries between Humans and Nature}

In the 'before' scenario on the Efolweni Village poster, there is a lot of vegetation around the house and 'nature' is seen to be encroaching on 'civilization'. The children and material objects are in direct contact with the earth, which has the status of 'dirt'. In the 'after' scenario, boundaries have been set - there is no vegetation in the domestic realm, nature has become mediated and there is no direct contact with the earth One boy sits on a chair and the other on a blanket and both wear shoes. The tap is mounted on a pedestal, and the toilet is placed on a concrete block. The shift from organic building materials (mud and wood) to manufactured materials (bricks and corrugated iron) also reflects this notion of organizing the environment by eliminating what is ideologically classified as 'dirt'.

Douglas in Purity and Danger (1966) wrote about the concepts of boundaries and insulations with regard to the purity and mixing of categories of discourse and organization. According to Douglas, "dirt offends against order. Eliminating it is not a negative movement, but a positive effort to organize the environment" (1966: 2). She argues that by 'cleaning' we separate, place boundaries, and make visible statements about the home we create out of the material house (68). This is pertinent to the Efolweni poster where the emphasis is on home in the 'after' scenario, which represents order, cleanliness, limited contact with the environment and clearly defined boundaries with nature. The Efolweni Village poster thus seems to say that the 'civilized' and the 'developed' can only be achieved through boundaries between humans and nature. Nature is represented as synonymous with underdevelopment and direct contact with nature is deemed undesirable, whereas circumscribed and controlled nature is represented as developed.

Boundaries between private and public spaces are defined and delimited around the notion of dirt, privacy and shame in this poster. For instance, the toilet has no door in the 'undeveloped' village, and is full of lies, but in the developed village it is represented as both 
clean and private. This reflects on a notion of propriety, which was a common discourse across all of the students' texts. 'Propriety' is a moral view on adherence to convention. Propriety operates through the internal regulation of behaviour as the effect of a particular emotional, political, economic heritage which allows the subject to be located in a particular social universe (Mayol 1998: 16 - 21).

In the Efolweni Village poster, propriety is inextricably linked to notions of 'development'. It is realized semiotically in the representations of the children's bodies, and emphasizes the importance of being clothed and the separation from nature mentioned above. In the 'before' scenario, both children are barefoot and partly unclothed - the older boy is wearing only shorts and the younger boy is only wearing a T-shirt. Their nakedness embodies the notion of propriety where shame is linked to dirt. In the 'after' scenario, the children are both fully clothed and wearing shoes. They have no blemishes on their skin and are wearing clean clothes.

Since a discourse of propriety was so prevalent in the students' texts and discussions, it is worth thinking about how such a discourse relates to education. Although propriety defines a moral view on adherence to convention in a specific context, it is also about being able to read a particular context and make decisions deemed appropriate to that context. In this sense, it is a crucial resource in decisions about meaning-making. A discourse like propriety could perhaps be used in the classroom to reflect on meaning-making and cultural practices. In upholding the collective and not the individual, the discourse of propriety can be aligned with certain notions of development and could perhaps be used in the development agenda. In this view of development, the community and the common good are emphasized over the individual and individual gain.

\section{Nostalgia and Utopianism as Signifiers of Transition}

Earlier, I pointed to the strong link between landscape, narrative and nostalgia. There is a complex interplay of nostalgia and utopianism within the students' poster. It is tempting to see a neat relationship between optimism and future orientation and between pessimism and an orientation that is retrospective. However, it is not always this clearcut. Nostalgia tends to evoke an impossibly positive past and utopianism evokes an impossibly positive future. Interestingly, both point to a sense of lack in the present. "Hostile to history and its invisible origins, and yet longing for an impossibly pure context of lived experience at a place of origin, nostalgia wears a distinctly utopian face, a face that turns toward a future-past, a past which has only ideological reality" (Stewart 1993: 23).

The Efolweni Village poster has a particular view of development which is necessarily about 'change'. This emphasis on change would seem to be antithetical to the conserving nature of nostalgia. Since change is equated to 'Westernization' in Efolweni, there is a strong emphasis on the move from traditional building forms, such as mud for houses, to more 'Western' forms of building materials, such as bricks. However, the idealizing thrust of nostalgia is preserved in the utopian terms in which development in Efolweni is envisaged. Development is represented as 'nurturing' through the presence of the mother-figure, as well as ordered, harmonious and clean. The utopianism is reflected in the colour of the poster card, where the before scenario is in yellow connoting dry, parched earth and barrenness, and the after scenario in blue, perhaps indicating 'blue skies', horizons, possibilities and the future. A utopian desire for things to work out harmoniously is reflected in the following student reflections: "...the other part [of the poster] is for the villagers to see what the future holds for them. It shows a happy and healthy life" and "According to the budgets made, everything seems to be falling into place". It would seem that nostalgia and utopianism are two very inter-related aspects of a society in transition such as South Africa, and thus emerge in ambivalent and dialogic ways in the students' representations.

\section{Temporal and Spatial Distancing}

I have already discussed how a prerequisite for nostalgia is an apprehension of the failings of the present. However, another prerequisite could also be a secular and linear sense of time. In the $20^{\text {th }}$ century Westernized world, a culture has been built upon a concept of time and 'progress' as linear, "a co-dependency emerged between the past, viewed as stable, and the future, seen as unknown and unknowable" (Otto 2005: 463). This perception of time is a prerequisite for nostalgia, as time lost cannot be instituted again.

Although the choice of Bantu to represent his village, Tabankulu, in a 'past' form could be construed as nostalgia, where the present is denied and the past takes on an authenticity of being, it is also a form of 'othering' where otherness is constructed in relation to temporality. The student chooses to represent Tabankulu in a temporally distanced way, in a phase in its development where there was no electricity. This was a particular period in his childhood. Fabian (in Hallam and Street 2000: 264) argues that the opposition present/past is linked to the oppositions of civilized/savage and subject/object, and is based upon assumptions of spatio-temporal distance: 
The process of 'othering' can thus be related to a linear view of time and development. However, a linear view is clearly insufficient when thinking about our experience of time interpretation and memory require a view of time more like a circle or spiral. According to Freeman, "we don't just live lines, moving inexorably through one thing after another; we live spirals of remembrance and return, repetition and reconfiguration, under the spell of ...mythopoeic desire" (1998: 47).

The notion of the 'other' is constructed through temporal distancing, but also through spatial distancing, through the construal of rural as 'lack', for instance. In some instances, the students from rural areas reproduce themselves and their lives in the village as 'other'. In this case, "self and other are mutually constitutive, identification and objectification go hand in hand" (Hallam and Street 2000: 250). Thus, contradictions and tensions in the perspectives on development are evident in the students' texts. The discursive conflicts also play out in the representation of 'us' and 'them' which sometimes mirrors the conflict between students' emerging identities as engineers and their previous identities as rural people.

In the Efolweni poster, the representation is made as an outsider to cultural practices - it encompasses an engineer's view of the village as a 'problem' to be solved as well as a patronizing view of the villagers as children in need of saving. The social is realized through the metonymic use of the children to represent the village as a whole. The decision to depict the situation through children is reminiscent of global media representations of development which are often linked to requests for 'aid'. The children have 'psychological salience' (Kress and Van Leeuwen, 1996: 61) as the viewer is invited to identify and empathize with them. The image of the children espouses a notion of development as aid which is a uni-directional process, rather than a process that combines both the local and the imported, the internal and the external.

I have argued that although the course emphasizes

sustainable development arising out of communities, the student poster represents rural as 'other' in contradictory ways. Development here is constructed as 'modernization' and 'westernization', and views of 'modernization' here become enmeshed in a linear view of development.

\section{Final Comments}

In the student poster that I looked at in this paper, development is largely constructed as the taming or harnessing of nature. In this view, nature is no longer seen as an agent in people's lives, nor the provider of mystical signs. In order to fully understand what sustainable development could possibly mean in a country like South Africa, this view of nature and the relation between the social and the natural need to be explored with the students. They need to be discussed alongside students' views of 'rural' and the perceptions of rural as 'lack'. The discourse of nostalgia also combines in interesting ways with the discourses of development and may be important in beginning to unpack the complex identity issues involved in living and working in a society like South Africa which is experiencing rapid transition. The tension between nostalgia for the past and an imperative to change (and the semiotic realization of this tension) can be highlighted and discussed as part of the curriculum.

One of my original observations when I first became interested in undertaking this research was that the relationship between technology and society was expressed to a far greater extent in the students' posters than in their formal written assessment tasks. It does seem that the visual genre enabled students to utilize discourses seldom used in engineering, such as the discourses of development, propriety, utopianism and nostalgia. The visual mode can perhaps enable and accommodate mixed domains of practice more easily than the written mode for this particular group of students, but aspects that may emerge in the oral mode in an unregulated classroom space (such as in interviews or class discussions) are still suppressed.

Making meaning in a tertiary context, on the one hand, needs to draw on and respond to discourses from the different domains of the students' sociocultural life world, the 'habitus' of the individual (Bourdieu 1991); and, on the other hand, it needs to respond to the discourses and practices within the institution. In traditional first year engineering courses, knowledge tends to be compartmentalized into bounded subjects like maths and physics, and these are not always applied directly to real world contexts. A curriculum which draws on students' experiences and discourses could be invaluable in this context, as it provides an opportunity for students to begin to interrogate their past situations as well as their aspirations. They also start to think critically of engineering as a profession within the context of South Africa. 


\section{References}

Archer, A. 2004. Access to academic practices in an engineering curriculum: drawing on students' representational resources through a multimodal pedagogy. Unpublished PhD thesis. University of Cape Town.

Archer, A. 2006. A multimodal approach to academic 'literacies': problematizing the visual/verbal divide. Language and Education. 20, 6. $449-462$.

Archer, A. 2007. Opening up spaces through Symbolic Objects: Drawing on students' resources in developing academic literacy practices in Engineering. English Studies in Africa. 49, 1. 189 -206.

Bernstein, B. 1996. Pedagogy Symbolic Control and Identity. Theory, Research, Critique. London: Taylor and Francis.

Bourdieu, P. 1991. Language and Symbolic Power. Cambridge, Massachusetts: Harvard University Press.

Calvino, I. 1979. Invisible Cities. London: Pan Books.

Douglas, M. 1966. Purity and Danger: An Analysis of Concepts of Pollution and Taboo. London: Routledge and Kegan Paul.

Freeman, M. 1998. Mythical time, historical time, and the narrative fabric of the self. In Narrative Inquiry 8, 1. $27-50$.

Hallam, E. and Street, B. (Eds) 2000. Cultural Encounters. Representing Otherness. London and New York: Routledge Halliday, M.A.K. 1978. Language as Social Semiotic. The social nterpretation of language and meaning. London: Arnold.

Head, L. 2000. Cultural Landscapes and Environmental Change. London: Arnold.

ledema, R. 2003. Multimodality, resemiotization: extending the analysis of discourse as multi-semiotic practice. In: Visual Communication. 2, 1.

Jewitt, C., Kress, G., Ogborn, J., Tsatsarelis. 2000. Materiality as an Aspect of Learning. In Zeitschrift fur Erziehungswissenschaft 3. Jahrg. Heft 2/2000, 5. 267 - 284

Kress, G. and Van Leeuwen, T. 1996. Reading Images. The Grammar of Visual Design London: Routledge.

Mayol, P. 1998. Living. In M. De Certeau, L. Giard, P. Mayol. (L. Giard (ed.) T. J. Tomasik trans.) The Practice of Everyday Life. Volume 2: Living and Cooking. Minneapolis/London: University of Minnesota Press.

Nakata, M. 2001. A changing indigenous perspective on education. Paper presented at the Eighth International Literacy and Education Research Network Conference on Learning. Anargyrios and Korgialenios School of Spetses, Greece

Otto, S. 2005. Nostalgic for what? The epidemic of images of the mid-20th century classroom in American media culture and what it means. In Discourse: studies in the cultural politics of education. 26, 4. $459-475$.

Sharp, J. 1988. Ethnic group and nation: The apartheid vision in South Africa. In E. Boonzaier and J. Sharp (Eds.) South African Keywords. The Uses and Abuses of Political Concepts. Cape Town and Johannesburg: David Philip.

Stewart, S. 1993. On Longing. Narratives of the Miniature, the Gigantic, the Souvenir, the Collection. Durham and London: Duke University Press. 